\title{
O COMPLIANCE COMO FERRAMENTA DE COMBATE À CRIAÇÃO DE CARTÉIS EM LICITAÇÓES PÚBLICAS E CORRUPÇÃO
}

\author{
COMPLIANCE AS A TOOL TO FIGHT CARTRIDGE \\ CREATION IN PUBLIC BIDDING AND CORRUPTION
}

\author{
EMERSON ADEMIR BORGES DE OLIVEIRA ${ }^{1}$ \\ Guilherme Prado BoHaC DE Haro ${ }^{2}$ \\ NAYARA IRAIDY MORAES FERRAS ${ }^{3}$
}

\section{RESUMO}

O presente artigo tem por objetivo tecer uma análise crítica acerca da atuação de cartéis em licitações no Brasil, quando associada à corrupção e conluios de ordem político-governamental, sob o prisma do que elucidou-se a partir da Operação Policial denominada "Jaleco Branco", deflagrada no Estado da Bahia, no ano de 2007, que apurou ilícitos desta monta, praticados por empresas privadas, associadas a agentes públicos. Por intermédio do estudo de caso e revisão bibliográfica, utilizando-se o método dedutivo-indutivo, pretende-se analisar a formação dos cartéis no âmbito das licitações na seara nacional, bem como as consequências negativas de tal instituto e o panorama do país para combate às práticas anticoncorrenciais, bem como a corrupção, apontando o Compliance como uma ferramenta de prevenção a ser utilizada, inclusive, pela Administração Pública.

PALAVRAS-CHAVE: Cartel. Licitação. Concorrência. Corrupção. Compliance.

1 Pós-Doutor em Democracia e Direitos Humanos pela Universidade de Coimbra. Doutor e Mestre em Direito do Estado pela Universidade de São Paulo. Coordenador-Adjunto e Professor Permanente do Programa de Mestrado e Doutorado em Direito da Universidade de Marília. Advogado e parecerista. ORCID iD: http://orcid.org/0000-0001-7876-6530. E-mail: emerson@unimar.br.

2 Doutorando em Direito pela Universidade de Marília. Mestre em Direito Negocial pela Universidade Estadual de Londrina. Especialista em Direito Civil e Processo Civil e em Direito do Trabalho, Processo do Trabalho e Direito Previdenciário pelo Centro Universitário Antonio Eufrásio de Toledo de Presidente Prudente. Professor do Centro Universitário Antonio Eufrásio de Toledo. Advogado. ORCID iD: http://orcid.org/0000-0001-9551-2671. E-mail: guilherme.pbh@hotmail.com.

3 Mestranda em Direito pela Universidade de Marília. Servidora Pública do Tribunal de Justiça do Mato Grosso. ORCID iD: http://orcid.org/0000-0003-0090-1442. E-mail: nayara.ferras@tjmt.jus.br. 


\section{ABSTRACT}

This article aims to make a critical analysis on the action of cartels in Brazilian public biddings when this fact is associated to corruption and political and government collusion from the point of view of what has been clarified from the Police Operation "Jaleco Branco", outbroken in the state of Bahia, in 2007, which ascertained felonies like that, committed by private companies that were associated to public agents. By means of case study and literature review, taking into account the deductive-inductive methodological approach, we intend to analyze the formation of cartels in the context of public biddings nationwide, as well as the negative consequences of such norm and Brazil's scenario for the fight against anti-competitive practices, as well as against corruption, highlighting compliance as a preventive tool that must be used, including the Public Administration.

KEYWORDS: Cartel; Public Bidding; Competitiveness; Corruption; Compliance.

\section{INTRODUÇÃO}

A defesa de um sistema de concorrência leal, tanto em prol de um sistema jurídico-republicano que se pauta sob o prisma da livre iniciativa, quanto sob o prisma do interesse público, faz-se de suma importância para o desenvolvimento socioeconômico de uma nação, sendo que, para tanto, devem ser implementadas, vez por todas, contemporâneas ferramentas e mecanismos que coíbam condutas concorrenciais que venham a colidir com a lealdade que apregoa o capitalismo como regime econômico, bem como que afrontem interesses Estatais e resultem em impactos negativos à sociedade.

Desse modo, o poder econômico, lato sensu, em consonância com os preceitos constitucionais pátrios, deve ser utilizado, sempre, para assegurar a todos uma existência digna, conforme os ditames da justiça social, da isonomia e da dignidade da pessoa humana.

Isto posto, faz-se de suma importância destacar que, conforme divulgado no Portal da Transparência (2020), a República Federativa do Brasil, no ano de 2019, contou com um orçamento de $\mathrm{R} \$ 3,26$ trilhões de reais para gerir suas atividades essenciais, sendo que parte deste recurso foi transferido aos agentes privados, por meio das licitações públicas que, regra geral, é o procedimento utilizado pela Administração Pública para realizar suas contratações e demais negócios jurídicos.

A simples análise dos dados licitatórios em âmbito nacional, faz-se como suficiente para que se extraía a conclusão de que discutir mecanismos que resultem na melhor forma de aplicar os recursos públicos, de modo a assegurar os fundamentos constitucionais, cumprindo também os objetivos republicanos, previstos no artigo $3^{\circ}$ da Carta Maior, é de salutar importância. Tem-se então a justificativa do presente estudo.

Neste sentido, conforme restará delineado ao curso do presente artigo, um dos maiores desafios para que se construa um sistema de licitação que atinja as finalidades constitucionais e republicanas, é, basicamente, o respeito aos princípios fundamentais da ordem econômica, em especial no que diz respeito à repressão e prevenção anticoncorrenciais.

A formação dos famigerados cartéis é exemplo de conduta anticoncorrencial, por excelência, sendo esta, inclusive, uma das mais nocivas - se não a mais prejudicial - a todo o sistema econômico e capitalista que rege um Estado Democrático de Direito. 
Sendo assim, o presente artigo analisará o que fora evidenciado e apurado a partir da deflagração da "Operação Jaleco Branco", que investigou, além da formação de cartel em processos de licitações, a colaboração, de forma direta ou indireta, de agentes públicos para a concretização do ilícito, mediante incontestes atos de corrupção.

Inicialmente, necessário se faz trazer os dados da Operação Jaleco Branco e as condutas praticadas pelos envolvidos, que violaram tanto preceitos constitucionais de ordem econômica, como a livre concorrência, bem como os princípios fundamentais da Administração Pública.

Na sequência, é trazido à tona o fenômeno do cartel, para que seja evidenciado, primeiramente, como infração à ordem econômica constitucional, para posterior recorte específico quanto à sua prática em processos licitatórios.

Em capítulo seguinte, será analisado como o Brasil tem atuado para combater as práticas anticoncorrenciais, como o cartel, bem como o apontamento do fenômeno da compliance, se aplicado à Administração Pública, como potencial mecanismo de contribuição para prevenção de prática da corrupção e, consequentemente, dificultar a formação de cartéis em licitações públicas, contribuindo então para a melhor aplicação orçamentária que, em última análise, advém do próprio capital da população, a partir do recolhimento tributário em geral.

O método utilizado para pesquisa utilizado foi o dedutivo-indutivo, com a presença de constante análise doutrinária, conceitual e casuística, buscando a resolução das controvérsias apresentadas por intermédio da elucidação de minúcias que envolvem o tema debatido, a fim de que se atingisse uma conclusão adequada e juridicamente plausível sobre a problemática abordada.

\section{A “OPERAÇÁO JALECO BRANCO” E O FENÔMENO DOS CARTÉIS}

A investigação criminal que se propõe como objeto de análise casuística fulcral para os fins a que se destina o presente trabalho, como cediço, se trata da denominada "Operação Jaleco Branco", realizada, em sede inquisitorial, no Estado da Bahia, partindo-se de apuração inicial sobre um suspeito esquema fraudulento envolvendo servidores do Instituto Nacional de Seguridade Social (INSS), os quais, mediante o recebimento de propinas, alteravam o sistema informatizado da Autarquia Federal, para fins de inserção, modificação ou exclusão de dados que permitiriam a emissão de Certidões Negativas de Débitos em favor de empresas privadas participantes do conluio, que utilizariam de referidos documentos para participar de licitações, ainda que possuíssem débito contraído a seu desfavor.

De acordo com a investigação, os empresários envolvidos utilizavam as Certidões fornecidas pelo INSS, quais sejam: Negativas de Débito - CND; e Positivas de Débito com Efeito de Negativas (CPD-EN), obtidas fraudulentamente, para participar de licitações nos serviços públicos daquele Estado. 
As empresas beneficiadas com as certidões falsas eram devedoras de vultosas quantias à Previdência Social. Segundo consta em peça acusatória (denúncia) oferecida pelo Ministério Público Federal (MPF), em face dos envolvidos, a fraude era sutil, porém deixava rastros visíveis e indiciosos, uma vez que todos os acessos aos sistemas informatizados do INSS ficavam registrados na própria plataforma.

A partir do desenrolar da investigação, entretanto, os fatos e elementos trazidos à tona davam conta de que, em verdade, o conluio fraudulento era praticado por uma complexa, sofisticada e bem estruturada quadrilha, composta por uma teia de empresários, seus empregados, bem como lobistas e servidores públicos, que se dedicavam, como uma equipe, à obtenção de lucro por intermédio de fraudes em processos de licitação

Dentre outras condutas, o grupo denunciado foi acusado de fraudar os processos de licitação para influenciar a contratação e pactuação de negócios jurídicos envolvendo os serviços públicos, às empresas de sua propriedade; impedir a realização dos processos de licitação, de modo a manter os contratos emergenciais superfaturados firmados com suas empresas; e firmar novos contratos emergenciais superfaturados.

Conforme narrou a denúncia, a organização era composta por quase 100 (cem) integrantes, dentre eles, um Procurador do Estado da Bahia e o Presidente do Tribunal de Contas do Estado da Bahia, à época, revelando assim ligação entre os agentes econômicos (empresas privadas) e os agentes públicos (representantes da Administração Pública).

Algumas empresas, inclusive, possuíam data de constituição e funcionamento que remontavam a datas que traduziam mais de 20 (vinte) anos de atuação, elemento a partir do qual extraiu-se que a organização criminosa atuava de forma estável e coordenada, há tempos, com finalidade fraudulenta enraizada em seus propósitos.

Em determinado momento, conforme consta na denúncia, na Ação Penal 510, junto ao Superior Tribunal de Justiça, mencionado grupo fora definido como:

Rede de pessoas, empresas e instituições envolvidas no direcionamento dos contratos de prestação de serviço no estado da Bahia. É a estrutura em que se assenta a OC com regras próprias, padrões de comportamento pré-definidos, sistemas de distribuição dos lucros ilícitos e defesa coordenada de seus integrantes.

A quadrilha contava com cerca de 20 (vinte) empresas que atuavam na área de limpeza, conservação, vigilância e portaria, todas vinculadas aos empresários integrantes da organização criminosa. Os registros perante a Junta Comercial dos integrantes do quadro societário e administrativo das pessoas jurídicas se davam, também, em nomes divergentes dos reais administradores do esquema.

Segundo apurações em sede policial, durante o período de sua atividade, a organização criminosa teria auferido lucros extremamente voluptuosos, que, segundo relatório elaborado pela Controladoria do Estado, tão somente com base no período compreendido entre os anos de 1997 a 2000, atingiram a cifra de $\mathrm{R} \$$ 1.379.252.584,65 (um bilhão, trezentos e setenta e nove milhões, duzentos e cinquenta e dois mil, quinhentos e oitenta e quatro reais e sessenta e cinco centavos).

Tendo em vista as diversas condutas criminosas realizadas pela quadrilha, que incluem, além da prática do cartel (infração à ordem econômica), atos de corrupção, o CADE não teria 
competência legal para realizar a investigação, conclamando a atuação dos órgãos de controle e do Ministério Público, como ocorrido.

É o que dispõe, inclusive, o próprio Conselho Administrativo de Defesa Econômica (CADE), ao escopo de suas orientações:

Contudo, é importante diferenciar o cartel em licitação das demais fraudes ao caráter competitivo dos certames licitatórios. Há diversos casos em que o CADE não tem competência legal para realizar a investigação, cabendo a atuação dos órgãos de controle e do Ministério Público. Por exemplo, quando várias empresas licitantes são do mesmo proprietário, ou quando há sócios administradores em comum entre as empresas licitantes, não estaríamos diante de um acordo entre empresas concorrentes, pois em ambos os casos tais empresas integrariam um mesmo grupo econômico de fato. Também há casos em que se poderia promover uma licitação competitiva, mas o administrador público ilicitamente incluiu cláusulas restritivas da concorrência no edital ou mesmo realizou uma contratação direta ilegal. Essas práticas não são, da mesma forma, de competência do CADE, e sim objeto de controle administrativo pelo Ministério Público e Tribunais de Contas. (CADE, 2018)

As práticas imputadas à quadrilha, conforme dito anteriormente, incluem a prática de cartel e atos de corrupção, tais como:

a) inserção de cláusulas ilegais nos editais para justificar a propositura de ações judiciais, mais especificamente mandados de segurança, com a finalidade de impedir a realização das licitações, invocando a nulidade que eles próprios fizeram inserir;

b) cooptação de eventuais concorrentes mediante o pagamento de valores ou a entrega de bens, em geral veículos, de modo a retirá-los da competição e garantir a escolha de suas empresas nos processos de licitação ou na contratação para serviços emergenciais;

c) corrupção de servidores públicos para obtenção de informações relevantes à consecução do objetivo criminoso;

d) falsificação e uso de documentos falsos;

e) compra de veículos como meio de ocultar a origem ilícita dos lucros provenientes da atividade delituosa. (BRASIL, 2007, p. 6)

As licitações, na área de atuação do grupo, eram sempre precedidas de ajuste entre eles para decidir quem figuraria como concorrente e quem venceria o certame, afetando, de modo a extinguir do certame público, a livre concorrência.

O vencedor escolhido pela quadrilha, como contraprestação por ter sido contemplado com a contratação junto ao Poder Público, efetuava o pagamento em dinheiro ou a entrega de bens, geralmente veículos, aos empresários concorrentes e aos desistentes do certame.

Desta forma, todos os envolvidos acabavam sendo beneficiados com o contrato público, em maior ou menor valor, a depender do potencial de suas empresas e da participação efetiva para conclusão da fraude.

A prática de cartel nas contratações públicas foi identificada diversas vezes nos últimos anos, o que resultou em uma grande quantidade de operações policiais buscando combater 
tal ilícito, entre elas: Vampiro [2004], Sentinela [2004], Sanguessuga [2006], Carta Marcada [2006], Fox [2006], Alcaides [2006], Jaleco Branco [2007] e Castelo de Areia [2009].

Nesse prisma, Lira (2012, p. 24) aduz que: "O prejuízo causado, ao estado brasileiro, por essa prática pode ser estimado na ordem das centenas de milhões de reais, considerando que as compras de bens, serviços e a construção de obras públicas pelo Estado representam parcela expressiva do seu PIB".

Os números trazidos pela Escola Superior do Ministério Público da União demonstram que, no ano em que foi deflagrada a operação em análise, outras 47 , relacionadas à criminalidade econômica e corrupção, também foram realizadas:

Em 2007, foram realizadas 188 operações, que resultaram em 2.876 prisões, 310 de servidores públicos e quinze de policiais federais. Desse quantitativo, 48 relacionadas à criminalidade econômica e corrupção, que resultaram em 1.094 prisões: Passe Livre, Aliança, Rio Nilo, Antídoto, Testamento, Malha Sertão, Ouro Verde, Kaspar, Lacraia, 274, Cacique, Paraíso, Navalha, Contranicot, Hiena, Bruxelas, Xeque-Mate, Zaqueu, Caipora, Rússia, Abatedouro, Reluz, Columbus, Águas Profundas, Aliança, Selo, Zebu, Catraca, Aposta, Zebra, Faxina, Persona, Ouro Branco, Metástase, X-9, Alquila, Rodin, Kaspar II, Vento Sul, Metamorfose, Carranca, Xadrez, Curto Circuito, Jaleco Branco, Casa Nova, Oitava Praga, Rapina e Al Capone. (ESMPU, 2016, p. 108)

Denota-se, portanto, a importância de aprofundar o presente estudo. Assim, nos itens seguintes, passa-se a analisar o fenômeno ilícito denominado por cartel, sua incidência nas licitações e como o país atua para combater tal prática que afronta a ordem econômica e traz grandes prejuízos, seja para o particular, seja para o Estado, seja para o interesse público, como um todo.

\section{O CARTEL E A ORDEM ECONÔMICA}

Antes de adentrar à análise do instituto do cartel, necessário destacar o contexto em que está inserido, em apreço aos principais princípios constitucionais que balizam a ordem econômica nacional, quais sejam, a livre iniciativa e a livre concorrência.

De início, faz-se necessário explicitar que a Ordem Econômica brasileira, aqui compreendida como um "conjunto de todas as normas (ou regras de conduta), qualquer que seja a sua natureza (jurídica, religiosa, moral, etc.), que respeitam à regulação do comportamento do comportamento do sujeitos econômicos" (MOREIRA, 1973, p. 67-71, apud GRAU, 2003, p. $55 / 56)$, é regida por diversos princípios basilares, sendo que os pilares centrais, dentre eles, são os princípios da livre iniciativa e da livre concorrência.

O primeiro deles é, inclusive, estampado pela Constituição Federal como fundamento do Estado Democrático de Direito, na esteira de seu artigo $1^{\circ}$, inciso IV, qual seja, "os valores sociais do trabalho e da livre iniciativa", princípios repetidos, de forma específica, pelo caput do artigo 170 enquanto fundamentos da ordem econômica. Além, o mesmo artigo ainda indica a "livre concorrência" como um de seus princípios basilares. 
Para Silva (2000, p. 767), "liberdade de iniciativa envolve a liberdade de indústria e comércio ou liberdade de empresa e a liberdade de contrato". Esmiuçando o conceito, Almeida (2004, p. 98) entende ser, a livre iniciativa, um princípio constitucional que existe para afastar a ingerência do Estado na atividade econômica, com a finalidade de evitar monopólios e conferir ao particular a liberdade de exercício de qualquer atividade que não esteja vedada por Lei.

A livre concorrência, por sua vez, não pode ser entendida como sinônimo, ou como equivalente da livre iniciativa, mas sim como uma vertente de referido postulado normativo. É, portanto, um princípio consagrado na Constituição Federal de 1988, cuja inobservância caracteriza infração à ordem econômica, acarretando prejuízo à coletividade.

Nesse sentido, para Grau (1991, p. 228), "a livre concorrência é pela Constituição de 1988 erigida à condição de princípio. Como tal contemplada no artigo 170, IV, compõe-se, ao lado de outros, no grupo do que tem se referido como 'princípios da ordem econômica'".

Ainda, de acordo com o raciocínio alinhavado, Almeida (2004, p. 110) entende que a livre concorrência possui, como finalidade, "buscar chances iguais para a disputa leal e igual na exploração de qualquer atividade".

Coaduna com tal entendimento:

A ordem econômica delineada pelo art. 170, IV, da Constituição Federal, além de fundada na valorização do trabalho e na livre iniciativa, tem como objetivo assegurar a todos a existência digna, conforme os ditames da justiça social, desde que respeitada uma série de princípios, dentre os quais, a livre concorrência, a defesa do consumidor e do meio ambiente, a propriedade privada e a função social da propriedade. (BONFIM, 2011, p. 171)

O princípio em comento visa garantir aos agentes econômicos, que atuam no mercado, condições de igualdade, mais precisamente isonomia quanto à oportunidade de competir.

A livre concorrência, portanto, tem por escopo garantir a todos quantos pretendam atuar no mercado uma condição de ingresso, buscando conquistar fatia dos consumidores, isto é, a garantia de atuação, em condições de igualdade, entre os demais agentes econômicos. (BONFIM, 2011, p.177)

Entretanto, há de se frisar que não se trata apenas de proteção ao direito subjetivo dos agentes econômicos, mas também de consumidores e da coletividade, que acabam por se tornar, em uma definição contemporânea dos princípios fundamentais da ordem econômica, os destinatários finais tutelados pela norma, atingidos pela sua finalidade prática:

A definição do alcance do princípio da livre concorrência, portanto, passa pela identificação do bem jurídico tutelado, tendo em vista que não há mais espaço no ordenamento jurídico posto para que o princípio da livre concorrência seja entendido apenas como um direito subjetivo dos agentes econômicos, como outrora prevaleceu durante o liberalismo econômico. Como afirma BERNARD DUTOIT, "na sociedade contemporânea, a proteção das concorrências não pode mais ser dissociada daquela dedicada aos consumidores e à coletividade em geral".

É que, conforme prescreve a Lei n. 8.884/94, a coletividade é a titular dos bens jurídicos protegidos pela lei de defesa concorrencial, sendo imperioso que se reconheça no princípio da livre concorrência um instrumento de efetivação de um bem maior, qual seja, a preservação de um mercado ajustado 
que tenha o condão de fomentar o alcance dos objetivos da ordem econômica. (BONFIM, 2011, p.178)

Para Bonfim (2011, p. 179), ainda, o princípio da livre concorrência deve ser visto como instrumento de alcance de um mercado livre que traga reflexos para a sociedade e o desenvolvimento dos agentes econômicos, visto que a ordem econômica é criada com o escopo de assegurar a todos existência digna, conforme os ditames da justiça social.

Desde que não haja exercício irregular do direito da livre iniciativa, poderá haver o domínio de determinado mercado pelo agente econômico, o que, evidentemente, deve decorrer de sua eficiência (art. 36, § $1^{\circ}$, Lei 12.529/2011). Veja-se:

0 ordenamento jurídico permite a vitória, por assim dizer, de um determinado agente econômico, desde que as regras do jogo sejam seguidas. Poderá haver sobreposição de um determinado agente num dado mercado relevante. A busca por maiores fatias de mercado é estimulada pelo ordenamento, desde que gere melhoria nos produtos ou serviços oferecidos e menores preços, tudo em função da concorrência entre os agentes econômicos. A vitória é rechaçada quando alcançada por meios não homologados pelo sistema como, v.g., a prática de preços predatórios e a criação de cartéis. (BONFIM, 2011, p.181)

Tem se, portanto, que o objetivo da aplicabilidade prática dos princípios da ordem econômica é, efetivamente, assegurar a existência real da concorrência, a partir de uma livre iniciativa, o que acaba por ser, em última análise, benéfico para o mercado e para sociedade como um todo. Qualquer prática que afronte tais princípios, deve ser combatida, como é o caso do cartel, que é tido como a mais gravosa de todas as infrações à ordem econômica.

A título introdutório, imperioso explicitar a definição clássica de concorrência desleal, para que, posteriormente, o estudo passe ao ponto fulcral a que se destina:

Consiste a concorrência desleal, em suma, na prática de atos de comércio e em procedimento reprovável destinado a desviar a freguesia do concorrente; eis porque o texto ressaltou ao prejudicado o direito de haver perdas e danos em ressarcimento de prejuízos causados por outros atos de concorrência desleal nele não previstos, tendentes a prejudicar a reputação, os negócios alheios, a criar confusão entre estabelecimentos comerciais ou industriais ou entre produtos e artigos postos no comércio.

Estes atos não se reputam crimes e não se sujeitam a pena; mas são delituais do ponto de vista do Direito Comercial, atos ilícitos que criam a obrigação de indenizar perdas e danos. (FERREIRA, 1960, p. 354)

Extrai-se, portanto, que, desde a definição clássica, os atos de concorrência desleal sequer seriam considerados, mas apenas a partir de sua análise específica como crimes, uma vez que tratam de prejuízos acarretados entre agentes econômicos, que não possuem o condão de causar danos à economia como um todo.

Entretanto, as infrações à ordem econômica, em razão do patamar potencialmente lesivo a todo sistema econômico-social capitalista vigente, caracterizam-se como atos de concorrência desleal qualificados, podendo ser, inclusive, tipificados como crimes.

Em consonância, vejamos:

O domínio econômico, como todo domínio, gera poder para seus detentores. 
todos existência digna, conforme os ditames da justiça social (CF, art. 170). Quando o uso desdobra em abuso, a própria Constituição impõe sua repressão (art. 173, §4..$^{\circ}$ (MEIRELLES, 2014, p. 757).

A operação policial mencionada no item anterior revela um cenário de cartel, que possuía, como alvo do conluio, fraude em processos licitatórios que afetava, diretamente, o Poder Público e o Erário. 0 cartel, infração gravíssima à ordem econômica, possui o condão de extinguir a concorrência, ou a torna fantasiosa, a ponto de ser identificada por muitos como pseudoconcorrência, diante do acordo prévio entre os agentes econômicos envolvidos a fim de dominarem o mercado.

Nesse sentido, o preciso conceito de cartel:

Cartel - Trata-se de um acordo entre empresas que passam a adotar decisões ou políticas comuns quanto a todos ou a um determinado aspecto de suas atividades. Por se tratar de um acordo, as empresas nele envolvidas não perdem a sua autonomia ou a sua individualidade. Elas apenas se submetem aos termos do acordo no seu particular âmbito de aplicação (NUSDEO, 2015, p 222).

Os agentes econômicos, que se unem para formação do cartel, optam por cooperar entre si, seja combinando preço, restringindo as variedades de produtos ou até mesmo dividindo mercado, tendo como resultado o aumento arbitrário da lucratividade em detrimento da autorregulação da própria economia como essência de seu desenvolvimento.

Denota-se que a Lei de Defesa da Concorrência não faz distinção entre as espécies de cartel. Aliás, a Lei sequer utiliza a expressão "cartel", trazendo, dentre o rol exemplificativo de condutas lesivas à ordem econômica, o acordo entre concorrentes para fixação de preços, redução de quantidades, divisão de mercados ou fraudes em licitação pública (art. $36^{\circ}, \S 3^{\circ}$, I).

Conforme destaca Almeida (2012, p. 219), para fiel configuração dessa infração, é imprescindível o acordo entre os agentes envolvidos na atividade econômica, de maneira a caracterizar a abusividade.

Para efeitos de classificação doutrinária, pode-se dividir os carteis em duas espécies, de acordo com o setor no qual o conluio entre os agentes econômicos é verificado, se privado ou se público.

A primeira, cartel de mercado, quando identificado na iniciativa privada, caracterizado a partir do acordo, combinação, manipulação ou ajuste, entre os concorrentes, de preços de bens ou serviços ofertados individualmente (cartel de fixação de preços, de compra ou de venda), da limitação da produção ou da comercialização de bens ou da prestação de serviços (cartel de redução de quantidades) e da divisão de mercados mediantes clientes, fornecedores, regiões, períodos ou outros (cartel de divisão de mercados). Tais hipóteses estão previstas, exemplificativamente, no art. $36, \S 3^{\circ}$, I, "a" a "c", da Lei de Defesa da Concorrência.

A segunda, cartel em licitações, prevista na alínea "d" do supracitado dispositivo e caracterizada a partir do acordo, combinação, manipulação ou ajuste de preços, condições, vantagens ou abstenção, dentro de um processo licitatório, pelos licitantes, com ou sem a participação da Administração Pública.

No âmbito internacional, convencionou-se denominar o cartel formado em licitações de bid rigging, que, segundo a OCDE (2009), "occurs when businesses, that would otherwise be 
expected to compete, secretly conspire to raise prices or lower the quality of goods or services for purchasers who wish to acquire products or services through a bidding process".

Tal prática ganha maior notoriedade quando identificada na iniciativa privada, tendo como exemplo típico e corriqueiro o setor de combustíveis. Entretanto, o setor público também é alvo, como vimos no curso da análise casuística viabilizada pelo presente estudo, e o seu combate tem sido cada vez mais intenso nos últimos anos.

Destarte, sem desconsiderar o relevo que assumem os carteis de mercado no ordenamento jurídico pátrio (contemplados nas searas penal, cível e administrativa), integra o objeto específico do presente trabalho a análise de carteis em licitações públicas e como a sua formação pode ser mitigada pelo fenômeno do compliance.

Passa-se então a analisar o cartel nas licitações e suas danosas consequências.

\subsection{CARTÉIS EM LICITAÇÓES PÚBLICAS E SUAS CONSEQUÊNCIAS}

A necessidade de contratação de obras, serviços, compras e alienações, realizadas pela Administração Pública, mediante processo de licitação que assegure a igualdade de condições a todos os concorrentes, advém de uma diretriz constitucional, insculpida no inciso XXI, do artigo 37, da Lei Maior.

Segundo Pestana (2013, p. 33), a licitação é um processo administrativo, promovido pela Administração Pública, previamente a determinadas contratações, com o objetivo de identificar a proposta conveniente para ser contratada.

O autor ainda aponta possíveis motivos para a escolha do processo licitatório. Veja-se:

Os motivos que ensejaram a sua criação podem ser os mais diversos: coibir ofensas ao caro princípio da isonomia; impedir o exercício da pessoalidade e preferência, pela Administração Pública, na escolha de determinados fornecedores e prestadores de serviços; identificar a proposta que seja mais vantajosa para a Administração Pública, etc. Todos esses motivos, de alguma maneira, estão voltados para preservar e proteger a coisa pública, expressão que utilizamos para representar o acervo da Administração Pública integrado por ativos, direitos, bens e interesses, bem como por encargos, passivos e deveres assumidos em desfavor da Administração Pública (PESTANA, 2013, p. 1).

A diretriz constitucional em comento fora regulamentada, na seara infraconstitucional, pela Lei n 8.666, de 21 de junho de 1993, que vige no intuito de estabelecer minuciosamente todas as condições, pressupostos e procedimentos a serem respeitados no âmbito de uma licitação.

Como bem lecionam Carvalho e Carvalho (2014, pp. 7-8), a legislação acima mencionada surgiu para normatizar o procedimentalismo licitatório e os requisitos de um contrato administrativo, obrigando, em seus termos, à observância dos dispositivos normativos por todos os órgãos da administração direta, fundos especiais, autarquias, fundações públicas, empresas públicas, sociedades de economia mista e demais entidades controladas, direta ou indiretamente, pela União, Estados e Municípios. 
Ademais, os autores trazem à tona sintético e preciso conceito sobre o processo licitatório:

A licitação destina-se a garantir a observância do princípio constitucional da isonomia, a seleção da proposta mais vantajosa para a Administração e a promoção do desenvolvimento nacional sustentável, previstos no artigo $3^{\circ}$, da Lei n. ${ }^{\circ}$ 8666/93 (BRASIL: 2010). A previsão desses objetivos na Lei de Licitações auxilia os doutrinadores e juristas do Direito Administrativo a traçar o conceito de licitação. (CARVALHO; CARVALHO, 2014, p. 8).

O que se espera é que as contratações realizadas pela Administração Pública sejam as mais vantajosas de acordo com o próprio interesse público, tendo produtos e serviços pelo menor preço e de melhor qualidade. A realização de um processo licitatório fraudulento, como é o caso do cartel avaliado pelo trabalho casuisticamente, causa graves prejuízos ao Erário e, consequentemente, à sociedade como um todo (contribuintes e consumidores, como destinatários finais dos princípios da livre iniciativa e livre concorrência).

Segundo Niebuhr (2011, p. 33), a licitação é procedimento administrativo que possui a celebração de um contrato administrativo, pela Administração Pública, como intenção, sendo que, a partir daí, terceiros interessados oferecem propostas a serem avaliadas de acordo com o interesse público.

Lira (2012) ressalta que "para alcançar tal objetivo, o instituto é regido, no Brasil, por um plexo normativo que deixa pouca liberdade ao gestor público na escolha de quem ele irá contratar".

Como vislumbrado ao curso do presente item, o cartel em licitações ocorre quando as empresas participantes do certame entram em acordo para definir quem será o vencedor, ou unem esforços na tentativa de manipular o resultado do processo licitatório para qualquer finalidade.

Para isso, tais empresas utilizam diversas estratégias, como a definição conjunta do valor das propostas, a redução do número de empresas licitantes nos certames, a apresentação de propostas sem a intenção de vencer a licitação, dentre outras, inclusive com esquemas de rotatividade de vencedores pré-definidos para simular uma concorrência inexistente.

A consequência disso é que a Administração Pública acaba por adquirir produtos e serviços em condições extremamente desvantajosas e os recursos públicos oriundos dos tributos pagos, que deveriam ser utilizados em prol da sociedade, são transferidos às empresas integrantes do cartel, que obtêm lucros ilícitos, em decorrência da ausência de concorrência efetiva.

Nesse sentido, o "Guia de Combate a Cartéis em Licitação", elaborado pelo CADE, aduz que:

Essa conduta altera a situação normal e esperada de efetiva concorrência do certame, imputando ao Estado condições menos favoráveis na contratação de bens e serviços, tais como preços mais elevados, produtos e serviços de qualidade inferior ou aquisição de quantidade menor do que a desejada. Em outras palavras, o cartel em licitação mina os esforços da Administração Pública em empregar de forma eficiente e eficaz seus recursos, com vistas a prover os bens e serviços necessários à população e promover o desenvolvimento do país, sendo, portanto, prejudicial a toda a sociedade. $(2019$, p.11) 
O painel de compras do governo federal revela que no ano de 2019 , foram realizados 80.632 processos de compras, totalizando o valor expressivo de $\mathrm{R} \$$ 45.902.704.189,85, incluindo diversas modalidades de licitação, dispensa e inexigibilidade (PORTAL DA TRANSPARÊNCIA, 2020).

Considerando as informações trazidas pelo CADE (2019, p. 14), com base nos dados da Organização para Cooperação e Desenvolvimento Econômico (OCDE), cartéis geram um sobrepreço estimado entre 10 e $20 \%$ se comparado ao preço em um mercado competitivo, causando perdas anuais de centenas de bilhões de reais aos consumidores.

Inúmeras são as consequências trazidas por esta prática, que mina a livre concorrência. O prejuízo reflete diretamente na coletividade, titular do bem jurídico tutelado, impactando ferrenhamente o desenvolvimento econômico-social do país.

Ainda, sobre as consequências da prática de cartel em licitações:

[...] os casos recentes investigados no contexto da Operação Lava Jato e apurados também no Conselho Administrativo de Defesa Econômica (CADE, 2017) deixam evidentes os potenciais danos econômicos, os abalos à estrutura de competição e, em última instância, os prejuízos para a confiança pública, provocados pelos cartéis em licitação (LACERDA, 2019, p. 112).

É cediço que os atos de corrupção e formação de cartel nas licitações públicas constituem ilícitos distintos. Entretanto, não é raro que ocorram em conjunto, de forma complementar e sob atuação com a mesma finalidade, exatamente como apurado na Operação Jaleco Branco, casuística avaliada pelo presente estudo, sendo recomendado que o combate a tais práticas seja feito de maneira integrada.

Passa-se a analisar como o país tem atuado para combater, ou, ao menos, reduzir as práticas nocivas à ordem econômica e, consequentemente, ao desenvolvimento nacional.

\section{O COMBATE AOS CARTÉIS NO BRASIL NOS PROCESSOS LICITATÓRIOS}

Diante da contemporaneidade globalizada, no que diz respeito aos ilícitos modernizados, quando analisadas as contratações públicas por intermédio de processos licitatórios, deve-se buscar mecanismos cada vez mais eficazes para mitigar os prejuízos causados à Administração Pública, frente ao cenário propício da licitação para a prática de cartel e condutas de corrupção.

A legislação brasileira prevê três esferas de punição às condutas anticompetitivas, como o cartel.

Como ilícito administrativo, compete ao CADE investigar e punir, infrações à ordem econômica, por força do artigo $4^{\circ}$ da Lei de Defesa da Concorrência. No ano de 2019, dos 707 processos julgados pelo CADE, 74 tinham como conduta apurada a prática de cartel (CADE, 2020). 
Na esfera cível também poderá ser ajuizada ação que tenha como causa de pedir a indenização por perdas e danos sofridos decorrentes das práticas que constituam infração à ordem econômica. A responsabilização civil tem respaldo tanto no Código Civil, quanto na Lei de Defesa da Concorrência.

No âmbito penal, a tipificação decorre da Lei 8.137/1990, que define os crimes contra a ordem tributária, econômica e contra as relações de consumo. 0 cartel, no âmbito da administração pública, também estará sujeito à Lei 8.666/1993.

Em harmonia com os demais dispositivos legais, a mais recente criação legislativa foi a Lei n. ${ }^{\circ}$ 12.846/2013, conhecida como Lei Anticorrupção, que disciplina a responsabilização administrativa e civil de pessoas jurídicas pela prática de atos contra a administração pública.

Neste diapasão, eis, como finalidade e instrumentos trazidos pela Lei Anticorrupção:

A Lei Anticorrupção (Lei $n^{\circ} 12.846$ de 2013) vem para preencher uma lacuna legislativa que permaneceu no direito brasileiro até sua promulgação, qual seja, determinar a responsabilidade objetiva da pessoa jurídica. Embora houvesse posicionamentos doutrinários a respeito do assunto, lei não havia sido editada até então. Inspirada na legislação americana Foreign Corrupt Practices Act e pelo Bribery Act, advindo do Reino Unido, e atendendo a Convenção sobre o Combate da Corrupção de Funcionários Públicos Estrangeiros em Transações Comerciais Internacionais, surgiu o novel diploma.

Em outros temas, a Lei Anticorrupção traz o instituto do compliance, que pode atenuar as penalidades no âmbito da própria lei, o acordo de leniência, punições que envolvem multa, publicação extraordinária da decisão, perdimento de bens e dissolução compulsória da pessoa jurídica (CEREN; CARMO, 2018, p. 38).

Ainda:

O âmago da lei é justamente a responsabilidade objetiva administrativa e civil das pessoas jurídicas caso pratiquem atos inadequados (que contrariem a sistemática da administração pública nacional e estrangeira), ou seja, haverá penalidade administrativa e civil, independente de dolo ou culpa; sendo constatada a lesão, as sanções cabíveis poderão ser aplicadas. Interessante anotar que quando a personalidade jurídica for utilizada para a realização de práticas ilícitas, permitir-se-á sua desconsideração (art. 14 da LAC) (OLIVEIRA; CEREN, 2019, p. 188).

Tramita junto ao Congresso Nacional, o Projeto de Lei do Senado $n^{\circ} 283$, de 2016, que tem como objetivo alterar a Lei n. ${ }^{\circ} 12.529$, de 30 de novembro de 2011 , que estrutura o Sistema Brasileiro de Defesa da Concorrência, a fim de, entre outras medidas, instituir o ressarcimento em dobro dos danos concorrenciais causados aos prejudicados que ingressarem em juízo, incentivando, portanto, a propositura da ação de reparação. Abaixo, transcrição da ementa do PLS:

Altera a Lei n. ${ }^{\circ}$ 12.529, de 30 de novembro de 2011, que estrutura o Sistema Brasileiro de Defesa da Concorrência e dispõe sobre a prevenção e repressão às infrações contra a ordem econômica, para tornar a multa à prática de cartel por empresa ou grupo econômico, proporcional ao tempo de duração da infração à ordem econômica; instituir o ressarcimento em dobro aos prejudicados que ingressarem em juízo, ressalvados os réus que assinarem acordo de leniência ou termo de compromisso de cessação de prática, além de 
outros incentivos ao acordo de leniência, desde que este seja feito mediante apresentação de documentos que permitam ao CADE estimar o dano causado; determina a sustação do termo da prescrição durante a vigência do processo administrativo; e torna a decisão do Plenário do CADE apta a fundamentar a concessão de tutela da evidência.

Nota-se que o atual arcabouço legal é resultado de muitos avanços ao longo do tempo. Entretanto, há que se reconhecer a necessidade de melhoria contínua, pois, em que pesem os esforços dos órgãos competentes, muitas das vezes, em razão da legislação processual, que torna moroso o processo, entre outros fatores, não se alcança a condenação dos culpados e impossibilita a lei atingir o caráter pedagógico e punitivo para qual foi criada.

Apesar do exposto, nota-se também o aumento dos esforços dos órgãos competentes para o combate ao cartel, como é o caso do CADE (2020) que, no período de 2015 a 2019, pela prática da conduta cartel, demonstra um aumento expressivo no valor das multas aplicadas, conforme se denota da análise da tabela.

\begin{tabular}{|c|c|c|}
\hline Ano & Conduta $\square$. & Total de Multas Aplicadas (R\$) \\
\hline 2015 & Cartel & $R \$ 173.242 .274,51$ \\
\hline 2016 & Cartel & $R \$ 136.263 .526,19$ \\
\hline 2017 & Cartel & $\mathrm{R} \$ 95.014 .064,74$ \\
\hline 2018 & Cartel & $R \$ 621.501 .253,85$ \\
\hline 2019 & Cartel & $R \$ 784.521 .604,95$ \\
\hline Total & & $R \$ 1.810 .542 .724,24$ \\
\hline
\end{tabular}

TABELA 1 - Multas aplicadas pelo CADE - Cartel (CADE, 2020)

Entretanto, nem sempre a atuação repressiva, mediante aplicação de multa, a criminalização de condutas e a previsão legal de reparação de danos é suficiente para que os agentes econômicos e Administradores Públicos corruptíveis se abstenham da prática dos atos ilícitos em questão.

Veja-se, não se pode negar a necessidade do controle repressivo das infrações à ordem econômica e da própria corrupção em sua essência. Entretanto, mais do que punir, é imperioso alterar um padrão de conduta, promover a mudança de cultura negativa sobre a prática de ilícitos que assola o Brasil.

A recorrente ligação dos cartéis em licitações, com casos de corrupção a partir de auxílio de Administradores Públicos, é exemplo de que não se pode pensar apenas na punição que, a depender das regras processuais, muitas vezes sequer é apta ao fim que deveria alcançar - garantir a tutela do interesse público -, bem como sequer há reparação razoável ao Erário.

É necessário, portanto, refletir sobre medidas que despertem o compromisso com a mudança de cultura, para que os preceitos constitucionais sejam cumpridos e então possamos pensar em justiça social, como prevê a Carta Magna. 
Nesse desiderato, pode-se pensar no compliance como um hodierno mecanismo aliado ao alcance de uma sociedade ética e justa, conforme demonstrar-se-á a seguir.

\subsection{OS CARTÉIS E O COMPLIANCE}

Não se pode olvidar que os crimes praticados contra a Administração Pública, em especial a prática de cartel, contam, muitas vezes, com a participação de agentes públicos, como visto no início deste artigo, associando-se, portanto, à corrupção.

Meirelles (2014, p. 123) assevera que "o ato mais afrontoso aos princípios básicos da administração e causador de prejuízos à sociedade é a corrupção no exercício da função pública". Assim, é necessário que mudança de postura tenha como objetivo não somente o setor privado, mas também a própria Administração Pública.

Neste diapasão, como cediço, a Lei $12.846 / 2013$ foi responsável por dar um salto na política anticorrupção brasileira ao instituir o mecanismo do compliance (programa de integridade) e também incluí-lo como atenuante de eventual sanção na apuração da responsabilização administrativa e civil de pessoas jurídicas pela prática de atos contra a Administração Pública, pois, de certa forma, estimula a empresa a aderir ao programa, iniciando assim a mudança almejada, rumo a um padrão de conduta mais ético e ilibado.

A terminologia, de origem inglesa, na tradução literal, significa "estar de acordo com". Compliance por ser entendido como estar em conformidade. "Em linhas gerais, consiste no dever das empresas de promover uma cultura que estimule, em todos os membros da organização, a ética e o exercício do objeto social em conformidade com a lei". (ASSI, 2018).

O programa de compliance não significa estar em conformidade, tão somente, com a legislação, respeitar métodos e procedimentos por si só, perspectiva que se revela reducionista, "uma vez que o mero cumprimento de regramentos e códigos de conduta não corresponde a sua real proficuidade" (GERCWOLF, 2019, p. 31). Mais que isso: "Em linhas gerais, o compliance envolve uma, consiste no dever das empresas de promover uma cultura que estimule, em todos os membros da organização, a ética e o exercício do objeto social em conformidade com a lei". ASSI, 2018).

Com efeito, o compliance pode ser entendido como um conjunto de mecanismos que fomentam a adoção de padrões culturais na organização - empresarial ou não - que o adere, os quais devem se conformar à ética, à integridade, à legislação e aos regramentos internos que norteiam as condutas esperadas de todos os colaboradores da organização, sem exceção, tanto que um de seus pilares é o chamado tone from the top, isto é, o envolvimento desde a mais alta Administração da empresa:

O compliance é sobre as pessoas, sejam elas decisores, gestores ou colaboradores, que devem pautar suas ações na responsabilidade corporativa, escolhendo, sempre, fazer o que é certo até que este comportamento se naturalize - seja nas condutas mais simples (relacionadas a hábitos e vestimentas), seja nas que impactam diretamente a operação. [...] (ASSI, 2018).

Neste sentido, disserta Fernanda Santos Schramm (2018, p. 207):

[...] mais do que a conformidade legal, o programa de compliance envolve estratégias que possibilitem uma alteração nos padrões culturais da empresa 
em relação à ética e às diretrizes que norteiam o ambiente regulatório, evitando os riscos inerentes à atividade empresarial e às punições legalmente previstas, com o consequente prejuízo à imagem da organização.

Em suma:

Pode-se distinguir o significado de compliance da simples conformidade à lei, sugerindo tratar-se de um estado dinâmico de observância legal e, portanto, estado de conformidade agregado a uma orientação de comportamento. [...]

Tais orientações de comportamento passam a ter relevância na medida em que são estabelecidas contratualmente, normalmente por meio de Códigos de Ética ou de Conduta, ou fixadas por lei, como no caso do compliance antilavagem, podendo seu descumprimento gerar distintas consequências jurídicas no âmbito cível, administrativo e penal.

É interessante verificar que o ordenamento jurídico nacional passou a dispor, no âmbito do criminal compliance, de espécies com distintas formatações na prevenção de prática de infrações penais, sobressaindo o compliance antilavagem, o compliance anticorrupção e o compliance antitruste (CARDOSO NETO; CORDEIRO; PAES, 2019, p. 90-91)

O compliance é visto com frequência no setor privado, já que, de um lado, o contexto econômico globalizado e de avanços tecnológicos impõem transparência e segurança nas relações comerciais, em sua maioria realizadas à distância e sem pessoalidade (SCHRAMM, 2018, p. 196), e de outro, a Lei anticorrupção trouxe algumas atenuantes que incentivam a adoção do programa, inclusive no tocante às penalidades aplicadas.

A implementação de um programa de compliance pelas empresas que atuam no setor privado, mas que também se relacionam com o Poder Público em processos licitatórios, se revela como importante mecanismo para evitar fraudes em licitações, sob diversos aspectos.

Pode-se inferir, isso, das próprias noções anteriormente traçadas acerca do compliance, no sentido de que a formação de um ambiente cultural íntegro e ético nas empresas acarreta, por consequência, em menor propensão à prática de corrupção e de fraude em licitação.

Fernanda Santos Charamm (2018, p. 102-114) destaca que as empresas que adotam um sistema de compliance efetivo contribuem a evitar fraudes no processo licitatório, desde a etapa preparatória, por meio de mecanismos que mapeiam e sinalizam "previamente as situações de risco, alertando funcionários e colaboradores para as possíveis consequências, individuais e coletivas, da prática de irregularidades", durante a fase externa da contratação, cabendo ao programa de compliance "evitar que os funcionários e representantes das empresas se utilizem de subterfúgios e manobras ilegais [...] para sararem-se vencedores a 'qualquer custo"', até o curso da execução do contrato, evitando-se "o envolvimento da empresa em situações de legalidade controvertida".

Todavia, sua aplicabilidade não está restrita às empresas privadas. Deve, também, ser utilizado pela Administração Pública. Tanto é que, por meio do Decreto n. ${ }^{\circ}$ 9.203/2017, houve a determinação de instituição do programa de integridade no âmbito da Administração Pública Federal.

Após inúmeros escândalos envolvendo agentes públicos, é uma atitude acertada instituir o programa de integridade também na iniciativa pública, de modo a torná-la ética e ilibada, ou ao menos buscar atingir este objetivo. Nesse sentido: 
O Compliance Público aponta para a uma efetivação inovadora ao Brasil como um mecanismo de integridade, calçado em um diagnóstico apurado, com avaliação dos riscos, monitoramentos, auditorias e denúncias que emanem a promoção de uma gestão íntegra e lícita na esperança que possa vir a ser a atitude mais acertada e rápida a retomada política do país, visto o Compliance Público ser um programa de integridade pública (SOUZA; MACIEL-LIMA; LUPI, 2019, p. 17).

Tal como ocorre no âmbito das organizações empresariais, o compliance se revela como importante ferramenta para mudança de padrões culturais da Administração Pública, direta ou indireta, fomentando a integridade daqueles que se encontram no exercício da Administração Pública, para que suas respectivas condutas se manifestem em conformidade à ética e, especialmente, aos ditames constitucionais.

Na medida em que a adoção do compliance público estimula a cultura de integridade, este se revela como um importante instrumento para a concretização dos princípios constitucionais que regem a Administração Pública, esculpidos no art. 37 da Carta Magna, sendo um importante mecanismo no combate à corrupção.

Para além disso, Susana Gercwolf (2019, p. 49-50) ressalta que a aplicação do compliance no setor público é capaz de "otimizar a gestão pública, em termos de melhoria e rapidez na qualidade e prestação dos serviços e de racionalização econômica e financeira".

O compliance pode não ser o instrumento derradeiro no combate à corrupção, mas certamente é um meio viável na consecução de mudanças culturais e um padrão ético mais digno, seja na seara privada, seja na pública.

\section{CONCLUSÃO}

Analisando todos os fatores expostos, cumpre salientar a importância do estudo dos fenômenos ilícitos do cartel, tendo como aliadas as práticas corruptivas de auxílio de Administradores Públicos, sendo que, a partir de recorte casuístico realizado sobre a "Operação Jaleco Branco", pôde ser demonstrada a relevância e complexidade de atuação de organizações criminosas desta finalidade, bem como a potencialidade lesiva de suas condutas à ordem econômica.

Restou, assim, delineado que as compras e licitações públicas geram um grande impacto econômico e possuem alta relevância no orçamento e gastos públicos; por essa razão, a alocação dos recursos deve ser cada vez mais assertiva e eficiente.

Traçadas as devidas análises conceituais e casuísticas, restou explicitado que as práticas de cartéis em licitações públicas estão, geralmente, ligadas a atos corruptivos institucionalizados, o que ajuda a manter longevidade do esquema e dificulta a detecção das fraudes, à exemplo da Operação Jaleco Branco.

Diante da potencialidade lesiva das condutas de cartel, aliadas à corrupção, que acabam por ferir, inclusive, preceitos de ordem constitucional, basilares do sistema capitalista e republicano brasileiro, o aprimoramento legislativo e a criação de instrumentos cada vez mais eficazes, tanto para fins de repressão, como de prevenção, mostrou-se de suma importância 
para eliminar ou, ao menos, mitigar as vulnerabilidades da Administração Pública, tutelando, assim, o interesse da sociedade em geral.

Surge, assim, o compliance como mecanismo benéfico de implementação tanto na iniciativa privada, quanto

Surge, assim, o compliance como mecanismo benéfico de implementação tanto na iniciativa privada, para fins de alteração de uma cultura escusa e corruptiva da população brasileira, quanto para utilização frente aos próprios órgãos da Administração Pública, para que a atuação em prol de um padrão de conduta ético e ilibado seja cada vez mais fomentada, e as medidas de repressão sejam menos necessárias, a fim de que os processos licitatórios atinjam sua finalidade constitucional, sob o prisma da equidade, isonomia e justiça social.

\section{REFERÊNCIAS}

ALMEIDA, Luiz Carlos Barnabé de. Introdução ao direito econômico. 4. ed. São Paulo: Saraiva, 2012.

ALMEIDA, Marcus Elidius Michelli de. Abuso do Direito e Concorrência Desleal. 1. ed. São Paulo: Quartier Latin, 2004.

ASSI, Marcos. Compliance: como implementar. São Paulo: Trevisan, 2018.

BONFIM, Diego. Tributação \& Livre Concorrência. 1. ed. São Paulo: Saraiva, 2011.

BRASIL. Superior Tribunal de Justiça. Ação Penal 510 - BA (2007/0297050-1). Relatório. Disponível em: https:// ww2.stj.jus.br/processo/revista/documento/mediado/?componente=ATC\&sequencial=30480525\&num_registro $=200702970501 \&$ data=20140317\&tipo=1\&formato=PDF. Acesso em 08 jan. 2020.

CADE - CONSELHO ADMINISTRATIVO DE DEFESA DA CONCORRÊNCIA. Guia de Combate a cartéis em licitação. Brasília: 2019. Disponível em http://www.cade.gov.br/acesso-a-informacao/publicacoes-institucionais/guias_ do_Cade/guia-de-combate-a-carteis-em-licitacao-versao-final-1.pdf. Acesso em: 08 jan. 2020.

CADE - CONSELHO ADMINISTRATIVO DE DEFESA DA CONCORRÊNCIA. CADE em Números. Brasília: 2020. Disponível em: http://cadenumeros.cade.gov.br/QvAJAXZfc/opendoc.htm?document=Painel\%2FCADE\%20em\%20 N\%C3\%BAmeros.qvw\&host=QVS\%40srv004q6774\&anonymous=true

Acesso em: 08 jan. 2020.

CADE - CONSELHO ADMINISTRATIVO DE DEFESA DA CONCORRÊNCIA. Perguntas sobre infrações à ordem econômica. Brasília: 2018. Disponível em: http://www.cade.gov.br/servicos/perguntas-frequentes/perguntas-sobre-infracoes-a-ordem-economica Acesso em 20 jan. 2020

CARDOSO NETO, Lauro Pinto; CORDEIRO, Nefi; PAES, José Eduardo Sabo. Criminal Compliance antilavagem: prevenção penal por agentes privados e o direito ao silêncio. Revista da Faculdade de Direito da UFPR, Curitiba, v. 64, n. 2, p. 89-110, mai./ago. 2019.

CARVALHO, Luciani Coimbra de; CARVALHO, Leonardo Chaves de. Contratações Emergenciais: Análise da Visão do Tribunal de Contas da União. Revista da Faculdade de Direito da UFPR, Curitiba, v. 59, n. 1, p. 7-34, 2014.

CEREN, João Pedro; CARMO, Valter Moura do. Lei anticorrupção brasileira e chilena: desafios no combate à corrupção. Revista da Faculdade de Direito da UFPR, Curitiba, v. 63, n. 3, p. 37-60, set./dez. 2018.

ESCOLA SUPERIOR DO MINISTÉRIO PÚBLICO DA UNIÃO. A investigação e a persecução penal da corrupção e dos delitos econômicos: uma pesquisa empírica no sistema de justiça federal: Tomo I. Arthur Trindade Maranhão Costa, Bruno Amaral Machado, Cristina Zackseski (organizadores). Brasília: ESMPU, 2016. 
Disponível em: https://escola.mpu.mp.br/publicacoes/series/serie-pesquisas/a-investigacao-e-a-persecucao-penal-da-corrupcao-e-dos-delitos-economicos-uma-pesquisa-empirica-no-sistema-de-justica-federal-tomo-1. Acesso em: 08/01/2020

FERREIRA, Waldemar. Tratado de Direito Comercial. São Paulo: Saraiva, 1960. v.1.

GERCWOLF, Susana. Compliance na Administração Pública Federal: instrumento de governança, gestão de riscos e sustentabilidade. Dissertação (Mestrado Político e Econômico) Universidade Presbiteriana Mackenzie, São Paulo, 2019.

GRAU, Eros Roberto. A ordem econômica na constituição de 1988: interpretação e critica. 2. ed. São Paulo: Revista dos Tribunais, 1991.

GRAU, Eros Roberto. A ordem econômica na constituição de 1988: interpretação e critica. 8. ed. São Paulo: Malheiros, 2003.

LACERDA, Natalia de Melo. A emergência dos programas públicos de integridade como instrumento de prevenção de cartéis em licitação. Revista De Informação Legislativa RIL, Brasília, DF, v. 56, n. 221, p. 111-130, jan./mar. 2019.

LIRA, Bruno de Oliveira. Cartéis em licitação: utilizando a teoria dos leilões para avaliar a legislação licitatória nacional. Dissertação (Mestrado em Direito) - Universidade Federal de Pernambuco, Recife, 2012. Disponível em: https://repositorio.ufpe.br/handle/123456789/10123. Acesso em: 18 jan. 2020.

MEIRELLES, Hely Lopes. Direto Administrativo Brasileiro. 41. ed. São Paulo: Malheiros Editores, 2015.

MINISTÉRIOS DA ECONOMIA, PLANEJAMENTO, DESENVOLVIMENTO E GESTÃO. Painel Processos de Compras. Brasília. Disponível em: http://paineldecompras.planejamento.gov.br/QvAJAXZfc/opendoc. htm?document=paineldecompras.qvw\&lang=en-US\&host=QVS\%40srvbsaiasprd04\&anonymous=true. Acesso em: 20 jan. 2020.

MOREIRA, Vital. A Ordem Jurídica do Capitalismo. Centelha: Coimbra, 1973.

NIEBUHR, Joel de Menezes. Dispensa e Inexigibilidade de Licitação Pública. 3. ed. Belo Horizonte: 2001.

NUSDEO, Fábio. Curso de economia: Introdução ao direito econômico. 9. ed. São Paulo: Editora Revista dos Tribunais, 2015.

OECD (OCDE) - Organisation for Economic Co-operation and Development. Guidelines for Fighting Bid Rigging in Public Procurement: helping governments to obtain best value for money. Paris: 2009. Disponível em: https:// www.oecd.org/competition/cartels/42851044.pdf. Acesso em: 10 set. 2020.

OLIVEIRA, Emerson Ademir Borges de; CEREN, João Pedro. Lei anticorrupção e acordo de leniência: apontamentos críticos. Revista dos Tribunais, v. 1010, a. 108, p. 181-207, dez. 2019.

PESTANA, Marcio. Licitações Públicas no Brasil: exame integrado das Leis 8.666/1993 e 10.520/2002. São Paulo: Atlas, 2013.

PORTAL DA TRANSPARÊNCIA - CONTROLADORIA-GERAL DA UNIÃO. Orçamento Anual. Brasília. Disponível em: http://www.portaltransparencia.gov.br/orcamento?ano=2019.

Acesso em: 20 jan. 2020

SCHRAMM, Fernanda Santos. O compliance como instrumento de combate à corrupção no âmbito das contratações públicas. Dissertação (Direito). Universidade Federal de Santa Catarina, Florianópolis, 2018.

SILVA, José Afonso da. Curso de Direito Constitucional Positivo. 17. ed. São Paulo: Melhoramentos, 767.

SOUZA, Silvia Regina; MACIEL-LIMA, Sandra; LUPI, André Lipp Pinto Basto. Aplicabilidade do compliance na Administração Pública em face ao momento político atual brasileiro. In: I Congresso Ibero-Americano de Direito Empresarial e Cidadania, 2018, Curitiba, Anais... Curitiba: UniCuritiba, v. 1, n. 24, 2018, p. 1-22.

Recebido/Received: 29.07.2020.

Aprovado/Approved: 26.09.2020. 